\title{
COVID-19 NO BRASIL E DIAGNÓSTICO DO PRESENTE: ANÁLISE DO DISCURSO E BIOPOLÍTICA
}

\author{
Daniel Verginelli Galantin (PUC-PR/PNPD)
}

Thiago Fortes Ribas (UFRJ)

\begin{abstract}
Resumo: A partir do pano de fundo da gestão política da pandemia de COVID-19, este artigo visa apresentar e discutir a noção foucaultiana de biopolítica articulando esta não apenas à questão da gestão política da vida, mas também com a especificidade de uma abordagem arqueo-genealógica. Neste sentido, destacamos a função da história e da análise do discurso na construção de um diagnóstico do presente, o que ajuda a destacar a especificidade do pensamento foucaultiano. Sustentamos hipótese de que a abordagem foucaultiana da biopolítica necessita de ajustes para a compreensão da gestão brasileira da pandemia. O principal ajuste seria a análise dos efeitos de centenas de anos de escravidão na sociedade brasileira. Contudo, o pensamento foucaultiano permite enxergar as racionalidades estratégicas de discursos que aparentam ser apenas irracionais, absurdos ou notícias falsas, os quais foram importantes no caso brasileiro. A exposição de milhões de pessoas aos riscos de contaminação é compreendida enquanto a radicalização de um corte biopolítico, constituído de modo sócio-histórico, que separa vidas que merecem ser protegidas de vidas que podem ou devem ser expostas ao risco de morte e outras decorrências da contaminação.
\end{abstract}

Palavras-chave: biopolítica; diagnóstico do presente; genealogia; pandemia; discurso.

Abstract: This article intends to present and discuss the foucaultian notion of biopolitcs in it's content not only of the the political management of life, but also the specificities of an archeogenealogical approach, having as a background the political management of the COVID-19 pandemics. We emphasize the function of history and the analysis of discourse to the construction of a diagnostic of the present, which helps to emphasize the specificity of the foucaultian approach. We also suggest that the foucaultian approach of biopolitics to understand the pandemics needs some adjustments in order to comprehend the Brazilian management of the pandemics. The main problem is the effects of hundreds of years of slavery to the constitution of Brazilian society. Nevertheless, foucaultian toughth can provide an understanding of the strategic rationality of discourses that appears to be just irrational, absurd or just fake news, but had a great importance to the Brazilian case. The exposal of millions of people to the risk of contamination is understood as a radicalization of a socially and historically biopolitical cut which separates lives that must be defended from those which ought to be exposed to the risks of death and other effects of contamination.

Key-words: biopolitics; diagnose of the present; genealogy; pandemics; discourse. 


\section{Introdução}

Chamar atenção para a singularidade do que vivemos a partir da eclosão da pandemia de Covid-19 pode parecer desnecessário. A obviedade de que estamos vivendo um momento extraordinário, no entanto, não está acompanhada de nenhum consenso sobre o que estamos vivendo. Ao contrário, a certeza sobre a raridade da situação é inseparável das incertezas vertiginosas provocadas por ela. Neste novo cenário muitos pensadores contemporâneos, no Brasil e no mundo, rapidamente tomaram posições. ${ }^{1}$ Entre projeções de futuros possíveis ou a denúncia da "invenção de uma epidemia" reflexões geradas desde fevereiro de 2020 alimentaram grandes e polêmicas especulações sobre o sentido deste acontecimento ainda em curso.

As estratégias teóricas pelas quais a questão é abordada trazem as marcas de pressupostos variáveis sobre o modo de abordar a história para pensar o que seria este estranho presente. Há aqueles que, seguindo uma herança das filosofias da história de inspiração hegeliana e marxista, pretendem compreender o presente à luz de um grande processo no qual seria possível a superação das contradições socioeconômicas. Nesta via, a pandemia poderia ser um golpe "no capitalismo global"3 ou o "fator extra-sistêmico" que levará ao seu colapso. Assim, caberia à filosofia atualizar a crítica diante dos novos fatos e refazer prognósticos orientadores da práxis em vista da superação da dominação pelo capital. O olhar para um futuro de emancipação e a centralização das questões políticas nas relações econômicas permite a tal estratégia teórica demarcar o sentido da atualidade tomando como referência uma grande continuidade histórica de lutas. Noções como liberdade e igualdade aparecem de formas bem definidas por uma interpretação histórica que as enxerga como aquilo que seria negado por uma organização social voltada

\footnotetext{
${ }^{1}$ No Brasil, além de textos críticos publicados em jornais e revista de grande circulação, temos iniciativas de editoras como a N-1 e a Boitempo de tornarem acessíveis online séries de artigos que propõe a reflexão sobre a pandemia. Vale notar que a revista acadêmica Voluntas: Revista Internacional de Filosofia publicou em modalidade contínua a edição especial sobre "Pandemia e Filosofia". Também disponível online e com grande impacto no debate internacional, temos a publicação da coletânea de textos Sopa de Wuhan. Pensamiento contemporáneo en tiempos de pandemias, que reuniu textos de Giorgio Agamben, Slavoj Zizek, Jean Luc Nancy, Franco "Bifo" Berardi, Judith Butler, Alain Badiu, Byung-Chui Han, Paul B. Preciado e outros autores.

${ }^{2}$ AGAMBEN, 2020, p. 17

${ }^{3}$ ZIZEK, 2020, p. 23

${ }^{4}$ BERARDI, 2020, p. 45
} 
à exploração dos trabalhadores nos sistemas de produção. Contra a ordem do poder capitalista, seria preciso, então, fazer funcionar uma verdade primordial com relação às ideologias. Assim, a revolução, capaz de pôr um ponto final na alienação capitalista, mantém-se como uma possibilidade sempre renovada por uma racionalidade emancipatória que, como protagonista de um grande processo histórico, atua ampliando a si mesma no enfrentamento dos obstáculos impostos à ação transformadora.

Por outro lado, é possível pensar várias estratégias teóricas diferentes. Dentre estas, há uma, em especial, que não compactua com os termos herdados das filosofias da história do século XIX, mas, ao contrário, constrói uma análise genealógica do presente justamente no distanciamento em relação a estes termos. Criticando o postulado de um processo dialético unificador, sua abordagem multiplica as perspectivas possíveis sobre a história e está focada naquilo que pode caracterizar o presente em sua singularidade em relação ao passado. Sem negar a exploração econômica, a estratégia teórica genealógica não constrói sua análise histórica tomando esta exploração enquanto o motor central de uma rede de causalidades. Trata-se de não submeter elementos heterogêneos a um princípio único, mas sim atentar aos acontecimentos de uma época, para então compreender como eles formam o "espaço de uma dispersão" . Na genealogia, a atenção não se volta para os modos de construção de um futuro redentor de uma história de injustiças, mas sim para a pergunta sobre as condições de possibilidade do nosso presente. Não se trata, portanto, de olhar o presente para encontrar nele os meios de realização de uma organização social em que a liberdade e a igualdade sejam finalmente conquistadas. Antes, trata-se de traçar diagnósticos sobre aquilo que nos tornamos, sobre o modo como pensamos e agimos, fazendo uma forma de crítica atenta aos perigos dos "gestos fáceis demais." abandonar a noção de liberdade, compreende a sua prática sempre em uma relação agonística com estruturas de poder imanentes a toda organização social. Sem ser indiferente às injustiças e às desigualdades, a estratégia teórica genealógica não se furta a colocar em questão a própria disposição de pensamento a partir da qual certas injustiças e desigualdades são percebidas e outras não. Contra os temas tradicionais da filosofia que invocam a necessidade de uma purificação da verdade em relação ao poder, sua

\footnotetext{
${ }^{5}$ FOUCAULT, 1969, p. 19

${ }^{6}$ FOUCAULT, 1994d, p. 180.
} 
abordagem faz funcionar uma "história política da verdade" ${ }^{7}$, na qual a produção de todo discurso sempre será articulada a relações de poder. Desconfiando da noção de revolução, propõe uma crítica constante às formas de saber e aos mecanismos de poder que formam nosso modo de ser atual. Colocando em questão até mesmo o postulado iluminista de uma razão capaz de atuar como sujeito da história, esta perspectiva filosófica irá questionar as condições pelas quais o homem foi considerado sujeito de razão e portador de uma teleologia.

Neste artigo, iremos explorar alguns aspectos desta segunda via - sempre pontuando a sua especificidade em relação a outras vias filosóficas possíveis. Em seguida, a partir de sua ótica, faremos breves considerações sobre a pandemia do novo coronavírus no Brasil, com o objetivo de apontar caminhos de um possível diagnóstico do presente. Assim, tanto a questão das condições de existência de discursos, trabalhada na arqueologia de Foucault, quanto a noção de biopolítica, trabalhada em seus estudos genealógicos, serão fundamentais para o desenvolvimento argumentativo deste artigo.

\section{Análise do discurso e espaço de uma dispersão}

Para além das diferenças em relação ao tratamento do tempo histórico, as duas estratégias teóricas mencionadas acima também mobilizam concepções irredutíveis sobre a tarefa da filosofia. Na primeira estratégia teórica mencionada, herdeira tanto das filosofias da história quanto da Teoria Crítica da Escola de Frankfurt, a filosofia não poderia se realizar teoricamente, mas somente na prática pela superação das estruturas alienantes próprias ao capitalismo. A orientação para esta relação entre teoria e prática já está em Marx, afinal, para ele, não basta aos filósofos interpretar o mundo de maneiras variadas, "o que importa é transformá-lo." 8 Por sua vez, na via nietzschiana desenvolvida nos estudos de Foucault, a experiência do saber também não se limitaria a uma teoria desvinculada da prática. No entanto, na perspectiva filosófico-genealógica, há uma ênfase no modo com que o pensamento é capaz de transformar não só as estruturas de poder vigentes e as construções de subjetividades ligadas a elas, mas também transformar a si

\footnotetext{
${ }^{7}$ FOUCAULT, 1988, p. 69.

${ }^{8}$ MARX, 2007, p. 533.
} 
mesmo em um exercício de problematização do presente. ${ }^{9}$ Trata-se, portanto, não de traçar prognósticos no presente para se alcançar um projeto futuro, mas antes de traçar diagnósticos sobre nós mesmos, os quais permitem uma crítica permanente sobre o modo como somos governados e sobre as práticas que nos constituem. A genealogia é um tipo de análise que questiona a formação de nossos próprios pensamentos e valores, para que não continuemos "estranhos a nós mesmos". ${ }^{10}$ Desta forma, a filosofia genealógica não profere um discurso de verdade capaz de orientar a política. A maneira com que verdade e política se articulam nas genealogias é atravessada por uma reflexão ética e por critérios metodológicos que impõem uma delimitação das pretensões, do alcance e das possibilidades de qualquer discurso. Ao contrário da posição que pretende dizer a verdade escondida atrás das falsidades, através da "minúcia do saber, [e] um grande número de materiais empilhados" ${ }^{11}$, as genealogias procuram mostrar em que condições são possíveis os sistemas de verdade pelos quais somos governados. Assim, o tipo de saber que elas produzem "não é feito para compreender, ele é feito para cortar" 12 , para cindir as cristalizações históricas de ações, pensamentos e instituições, restituindo mobilidade às nossas práticas. A intensidade política gerada nas genealogias está na exposição de um jogo múltiplo de forças, comumente abafadas quando se busca um suposto apaziguamento com o recurso aos universais. Assim, as próprias pesquisas genealógicas incidem como força neste jogo em que se disputa inclusive os critérios da validação discursiva, uma vez que as separações entre o verdadeiro e o falso não são tomadas como dados do puro conhecimento, mas consideradas em posições estratégicas de discursos.

A chegada das análises de Foucault em uma genealogia das estruturas de poder que nos atravessam em nosso presente é marcada pelo "ponto de vista de uma história dos discursos". ${ }^{13}$ É pela análise das condições de possibilidade de discursos sobre a loucura, sobre a criminalidade ou sobre a sexualidade que surgem, para Foucault, a emergência histórica de estruturas nas quais estão vinculadas formas de saber, de poder e de subjetivação. Para que uma tal análise se torne possível, primeiro, é necessário se

\footnotetext{
${ }^{9}$ Para Foucault, “o saber convida hoje a fazer experiências sobre nós mesmos.” (FOUCAULT, 1994a, p.155).

${ }^{10}$ NIETZSCHE, 2009 , p. 7.

${ }^{11}$ FOUCAULT, 1994b, p. 136.

${ }^{12}$ FOUCAULT, 1994b, p. 148.

${ }^{13}$ FOUCAULT, 1988, p. 78.
} 
desprender de pressupostos recorrentes que impedem o aparecimento da singularidade histórica destas estruturas. Para Foucault, a realização das análises genealógicas exige que se contorne muitos dos pressupostos que aparecem sob a chancela dos "universais antropológicos". ${ }^{14}$ Aqui, temos a questão da fundamentação irrefletida da verdade e da continuidade histórica na figura do homem como sujeito intemporal de conhecimento. A presunção de que a verdade e o sujeito seriam a-históricos, ou a de que suas formas desalienadas são conquistadas progressivamente, impedem que sejam percebidas as construções de sistemas históricos nos quais encontramos formas determinadas de verdades e de subjetividades. Assim também, vinculada à naturalização do homem como sujeito de conhecimento, temos a suposição da "antinomia entre saber e poder" ${ }^{15}$, ou seja, se o homem realiza a sua finalidade no ato de conhecimento, este ato não faz mais do que revelar uma verdade necessária. Apartado das relações de conhecimento, o poder é pensado de uma forma ingênua como obstáculo à verdade. Desta forma, nem os discursos de verdade são percebidos em suas localizações estratégicas, nem os mecanismos de poder são percebidos enquanto instâncias produtoras de verdades. Uma história dos pensamentos com tais pressupostos não será capaz de realizar uma genealogia ou uma história política da verdade, mas apenas a narrativa das "tomadas de consciência" do homem em seu caminho da libertação. ${ }^{16}$

Desta forma, a pressuposição do homem como sendo, por um direito natural, sujeito de conhecimento, carrega consigo uma visão sobre a história na qual a sua racionalidade apartada dos jogos de poder iria aos poucos despertando e revelando uma verdade imperativa, uma vez que livre de quaisquer injustiças porque fundada na essência humana. Sob a forma de uma narrativa contínua dos percalços percorridos pelo homem até o encontro com sua essência, esta historiografia se dirige aos documentos históricos somente em um momento derivado, que acontece para comprovar suas especulações que são, de fato, seu ponto de partida. Contra este olhar histórico totalizante que faz aparecer apenas aquilo que confirma as hipóteses de uma linha causal unificadora do processo temporal, a escuta genealógica afirma a necessidade de dar voz aos discursos para fazer

\footnotetext{
${ }^{14}$ FOUCAULT, 1994d, p. 634.

${ }^{15}$ FOUCAULT, 1994b, p. 570 .

${ }^{16}$ FOUCAULT, 1969, p. 22.
} 
aparecer aquilo que a análise documental de um dado momento permite afirmar. $\mathrm{O}$ diagnóstico genealógico, assim como o médico que examina seus pacientes, precisa auscultar os materiais levantados, pois serão eles a fonte primeira de sentido para compreensão dos acontecimentos. Assim, os discursos não devem ser tratados como projeções de um pensamento que acontece inicialmente na consciência do sujeito, o que justificaria a análise privilegiar a interrogação da consciência e desmerecer a importância dos discursos. Colocando os discursos uns em relação aos outros para compor o jogo de suas diferenças e de suas distâncias em um mesmo espaço de sentido, a análise genealógica combate o tema transcendental de um pensamento anterior aos discursos e que teria lugar no sujeito, uma vez que será neste espaço discursivo que diferentes tipos de sujeitos são formados. Ou seja, na genealogia, a anterioridade não é do sujeito, mas dos sistemas discursivos e institucionais que dão lugar a variadas formas de construção de subjetividades.

No livro $A$ arqueologia do saber vemos que, realizando suas análises de discurso, Foucault pretende "emancipar a história do pensamento de sua sujeição transcendental". ${ }^{17}$ Construindo-se em oposição aos temas transcendentais, a análise discursiva foucaultiana produz suas bases na complexificação do trabalho sobre a história. Se não pressupõe um sujeito de conhecimento que aos poucos conquista o seu direito a verdade, tampouco sustenta uma concepção da realidade em que as coisas seriam dadas, como se coubesse ao sujeito apenas desvenda-las. Nem o homem é tomado como um sujeito natural de conhecimento, nem as coisas do mundo são tomadas como objetos naturalmente aptos a serem conhecidos. Tanto na constituição dos objetos quanto dos sujeitos, a realidade é pensada por Foucault sempre em sua historicidade, sendo preciso compreendê-la a partir da problematização das práticas que a constituem. Portanto, a análise foucaultiana não se identifica com uma história do conhecimento e não pressupõe uma teoria do conhecimento, mas deve ser entendida como uma história dos saberes que investiga as condições históricas de existência dos sistemas de pensamento. Em outras palavras, sua análise se volta à ordem histórica das práticas discursivas e extradiscursivas que produzem

${ }^{17}$ FOUCAULT, 1969, p. 264. 
e condicionam as regras do verdadeiro e do falso, sendo a verdade pensada como um resultado de tal ordem.

Desta forma, para que as práticas discursivas sejam percebidas enquanto produtoras de realidades históricas, faz-se necessário um desvio em relação à forma habitual de se tratar a verdade e suas formas de fundamentação. Ao invés de se realizar uma investigação sobre a essência sempre secreta da verdade, busca-se, na materialidade dos enunciados, os momentos de formação e de transformação dos sistemas de pensamento nos quais essências são construídas "peça por peça a partir de figuras que lhe eram estranhas." 18 Para Foucault, este trabalho histórico que se volta aos discursos como práticas que produzem realidades precisa ser feito considerando-os em sua exterioridade. Fugindo aos temas transcendentais, não se deve tratar o discurso como aquilo que esconde um núcleo de significação que seria anterior, mas antes questionar, nos próprios enunciados, a construção de um sistema de pensamento que carrega as suas condições de possibilidade. Em um sistema de relações entre diferentes enunciados, as práticas discursivas produzem objetos, tipos de enunciação, conjuntos conceituais e estratégias marcadas pela singularidade de um "jogo de regras" 19 de um determinado tempo histórico. A análise discursiva de Foucault combate a ilusão de que qualquer coisa poderia ser enunciada em qualquer época, como se os objetos fossem dados, ou a ilusão de que para enunciar algo não importa qual posição se ocupa ou quais conceitos e quais estratégia se utilizam. Estes elementos discursivos - objetos, posição de enunciação, grupos de conceitos e táticas enunciativas - precisam ser analisados em suas regras de formação que aparecem em um espaço de tempo. Assim, a leitura do sentido das práticas discursivas guarda maior rigorosidade quando referida ao espaço em que são possíveis uma dispersão de enunciados, em suas oposições, suas hierarquias, suas manutenções ou seus esquecimentos. Trata-se de resguardar a análise na "dimensão da exterioridade" ${ }^{20}$, ou seja, justificar a inteligibilidade dos discursos no jogo de regras encontrado na materialidade do que foi efetivamente enunciado. A inteligibilidade é construída através de um recorte deliberado sobre um dado material de uma mesma série de acontecimentos. Assim, para a

\footnotetext{
${ }^{18}$ FOUCAULT, 1994b, p. 138

${ }^{19}$ FOUCAULT, 1994a, p. 676.

${ }^{20}$ FOUCAULT, 1994a, p. 682.
} 
análise discursiva foucaultiana, é preciso reconhecer certa artificialidade da construção de toda análise histórica. Há um caráter ficcional e necessariamente político na descrição dos acontecimentos discursivos, pois esta descrição é sempre parcial e situada em uma posição estratégica.

Em sua maior parte, as análises históricas realizadas por Foucault foram dirigidas às condições de possibilidade das ciências humanas, saberes que compartilham um solo e uma temporalidade comuns com o nascimento de várias formas de poder e de subjetivação que caracterizam nosso presente. Ao mesmo tempo que a sistematicidade dos discursos científicos permite uma organização e uma delimitação das análises, ao voltar-se às ciências humanas, o estudo das relações entre práticas discursivas e práticas extradiscursivas desemboca no enfoque privilegiado das relações entre as formações de saberes, estruturas de poder e formas de subjetivação. No entanto, a análise dos acontecimentos discursivos não é limitada ao domínio das ciências humanas. ${ }^{21} \mathrm{O}$ diagnóstico a partir das ferramentas de análise que investigam a formação de sistemas de pensamento pode ser realizado em diversos domínios discursivos, possibilitando uma visão sobre nós mesmos no presente livre dos prejuízos transcendentais das filosofias da história.

De certa forma, aquilo que será mobilizado por Foucault ao tratar da biopolítica é o estudo das regularidades e desníveis discursivos, e notadamente, sua relação com determinados mecanismos de poder. Apresentaremos o conceito para, posteriormente, tentar utiliza-lo para mostrar qual forma de diagnóstico do presente ele pode proporcionar, assim como alguns dos seus limites.

\section{Genealogia, biopolítica e racismo}

A pesquisa foucaultiana a respeito da biopolítica é uma das partes do seu trabalho que mais foi comentada e, ao mesmo tempo, que mais ensejou pensadores a tomarem rumos próprios de pensamento. É desta forma, seguindo um caminho próprio, que, por exemplo, Giorgio Agamben, Roberto Esposito, Antonio Negri, Michael Hardt, Maurizio Lazzarato, Judith Butler e Achille Mbembe desenvolveram parte de seus pensamentos.

\footnotetext{
${ }^{21}$ FOUCAULT, 1994a, p. 710.
} 
Para eles, o diálogo com Foucault serviu de mola propulsora para trilhar um caminho distinto. Contudo, pretendemos recuperar um pouco da especificidade da maneira com que o tema da biopolítica surge no pensamento de Foucault. Não se trata de fazer isso de modo exaustivo, mas antes, através da retomada desta especificidade, de apontar um pouco para a atualidade deste conceito, assim como para os limites que sua leitura pode fornecer ao contexto brasileiro durante a pandemia.

A primeira e principal característica da abordagem foucaultiana da biopolítica a ser ressaltada deve ser o fato de que ela é fundamentalmente uma genealogia histórica. Isso ajuda a diferenciar a abordagem foucaultiana daquela de pensadores que têm, para com a biopolítica, uma abordagem ontológica. Por exemplo, jamais encontraremos em Foucault afirmações que possam sugerir que a biopolítica é parte de uma estrutura milenar, que remete a um aparato teológico-político da soberania, como é o caso no pensamento de Agamben $^{22}$. Muito embora, no pensamento de Roberto Esposito, a biopolítica não remeta a fundações milenares, mas sim a uma forma moderna de poder (mais próximo da ótica de Foucault, portanto), Esposito parece explorá-la a partir de um ponto de vista fundamentalmente conceitual. Os episódios evocados no começo de $B_{i o s}^{23}$, por exemplo, são explicados por conceitos de teorias exploradas e problematizadas pelo livro inteiro. Isso se dá diversamente em Foucault, que faz com que os conceitos emerjam do entrecruzamento entre pesquisa em arquivos e reflexão conceitual. Logo, os conceitos foucaultianos são construídos também em diálogo com pensamentos que não se resumem a fontes de arquivos históricos. Mas esse diálogo é sempre atravessado, posto à prova e modificado pelo material analisado, que consiste fundamentalmente em práticas sociais (discursivas e extradiscursivas) delimitadas histórica e geograficamente. Evidentemente, não se trata de invalidar ou fragilizar as análises de Agamben ou Esposito através desta comparação. Mas é preciso ter o cuidado para relevar que, muito embora o conceito de

\footnotetext{
${ }^{22}$ No prefácio do primeiro livro de Homo Sacer, Agamben diz procurar o ponto em que se articulam o poder soberano e a biopolítica. Pois “(...) a implicação da via nua na esfera política constitui o núcleo originário - ainda que oculto - do poder soberano. Pode-se dizer, aliás, que a produção de um corpo biopolítico seja a contribuição original do poder soberano. A biopolítica é, nesse sentido, pelo menos tão antiga quanto a exceção soberana. Colocando a vida biológica no centro de seus cálculos, o Estado moderno não faz mais, portanto, do que reconduzir à luz o vínculo secreto que une o poder à vida nua, reatando assim (segundo uma tenaz correspondência entre o moderno e o arcaico que nos é dado verificar nos âmbitos mais diversos) com o mais imemorial dos arcana imperii" (AGAMBEN, 2002, p.14).

${ }^{23}$ ESPOSITO, 2017.
} 
biopolítica tenha como seu centro as relações entre política e vida, esse conceito não remete a uma mesma base filosófica nestes autores.

Como vimos anteriormente, no pensamento de Foucault, o trabalho histórico da filosofia não é orientado por nenhuma lógica que sustente um desenvolvimento teleológico. Numa entrevista de 1977, intitulada "Não ao sexo-rei", Foucault afirma claramente que seu objetivo é pensar o que somos nós em nossa transitoriedade. Isso significa que tal diagnóstico não pode se servir de qualquer elemento ahistórico que funcione enquanto um fundamento, tal como parte da filosofia outrora fez:

\begin{abstract}
(...) eu diria que por muito tempo a questão da filosofia foi a seguinte: 'nesse mundo em que tudo perece, o que é aquilo que não passa? Com relação àquilo que não passa, o que somos nós, nós que devemos morrer?'. Parece-me que desde o século XIX, a filosofia não para de se aproximar da seguinte questão: 'o que é que se passa atualmente, e o que somos nós, nós que talvez não sejamos nada mais e nada de diferente daquilo que se passa atualmente?' A questão da filosofia é a questão deste presente que é nós-mesmos. É por isso que a filosofia hoje é inteiramente política e inteiramente historiadora. Ela é a política imanente à história, ela é a história indispensável à política. ${ }^{24}$
\end{abstract}

É importante termos em consideração essa figura do diagnóstico do presente quando pensamos a biopolítica em Foucault. Como já vimos, os diagnósticos genealógicos não se confundem com prognósticos realizados para traçar novas estratégias que guardam como referência um mesmo problema central. Neste sentido, esta ideia de diagnóstico é importante na medida em que indica que a biopolítica diz respeito a nós mesmos em nossa atualidade. A biopolítica é uma das racionalidades políticas - não a única, mas talvez uma das principais - que nos constituem enquanto aquilo que somos. Nada disso impede que se faça, e que se deva fazer críticas quanto a algumas de suas facetas. Nada disso também deve conduzir à afirmação conformista e pessimista de que somos prisioneiros completamente determinados pelo funcionamento atual do dispositivo biopolítico. Enquanto racionalidade política, este dispositivo é constituído por um conjunto de práticas institucionais e de saberes surgidos desde o final do século XVIII. Trata-se de um conjunto de saberes e mecanismos institucionais que visam regular os fenômenos vitais de uma população. Sempre há um antes, e sempre pode haver um depois, mas, se queremos 
entender o que se passa hoje, é importante evitar pretensões de previsão futura. Antes de se aventurar em especulações filosóficas futuristas, atentar ao horizonte biopolítico atual nos permite questionar certas formas de gestão da vida, principalmente por elas deixarem de lado certas vidas.

Em que contexto a noção de biopolítica aparece no pensamento de Foucault? Ela aparece em meio a um conjunto de pesquisas sobre as formas de controle social da penalidade, da loucura e da sexualidade que de forma alguma dizem respeito apenas a esses âmbitos da sociedade. Desde seus estudos sobre o poder disciplinar, Foucault sempre ressaltava como esses poderes foram as condições políticas de possibilidade para o desenvolvimento do capitalismo. Sob a lente genealógica, esses poderes não são uma superestrutura garantidora da exploração do trabalho sob ameaça coercitiva. Antes, eles são estratégias para a extração de trabalho dos corpos. Os corpos das pessoas não estão aptos por si mesmos para o trabalho em manufaturas e fábricas. Quando se tratou de fazer trabalhar em fábricas pessoas que antes moravam e trabalhavam no campo, fizeram-se necessárias uma coação e uma vigilância incessantes. Com o advento das manufaturas industriais, as riquezas tornaram-se mais móveis, e os trabalhadores ficaram mais próximos tanto desses bens quanto do maquinário que os produziam. Com isso, técnicas de vigilância ganharam centralidade, pois uma eventual revolta causaria enormes danos aos proprietários, maiores que aqueles causados por revoltas no campo. Com a implementação das disciplinas, portanto, houve ainda uma "inversão funcional" ${ }^{25}$ de seus usos. O foco passa da preocupação em neutralizar riscos de populações desocupadas, para a extração da utilidade dos indivíduos.

Logo, as práticas sociais de controle que parecem tão específicas e restritas à loucura, ao crime e à sexualidade, na verdade, atravessam a sociedade toda. A forma com que uma sociedade define e lida com sua margem diz muito sobre o seu centro. Neste contexto, há uma vertente da pesquisa de Foucault que investiga como a psiquiatria, ao incorporar teses biológicas como a da degenerescência, abriu espaço para o racismo biológico. É importante notar que o conceito de biopolítica aparece num livro dedicado a mostrar como a sexualidade foi investida por uma gama de poderes, sendo ela a dimensão 
em que se cruzam as disciplinas dos corpos e o controle biopolítico da população. Porém, no início de 1976, ano em que é publicado o volume 1 de História da sexualidade, a noção de biopolítica aparece também no curso intitulado Em defesa da sociedade. Vejamos, também, o contexto em que esta noção aparece no curso.

Entre a terceira e quarta aula de Em defesa da sociedade, Foucault mostra como, na Europa, surgiu um discurso que compreende a política não nos termos do contrato e da legitimidade ou opressão, mas nos termos da guerra entre raças e da submissão ou repressão. Enfrentando-se com o pensamento contratualista clássico, entre os séculos XVII ao XIX, este discurso foi uma forma de pensamento histórico-político que explicava o poder não nos termos de sua fundamentação ou legitimidade, mas que mostrava como o poder político provinha do resultado de um conflito que algum grupo ganhou e que conseguiu, até então, manter essa vitória. Ou seja, depois de ganho o conflito, a ordem social é arranjada de forma a garantir que essa vitória se prolongue, de maneira que a manutenção da ordem política seria a manutenção da guerra por outros meios. Trata-se de um discurso de aristocracias que lutavam contra a centralização do poder na França da época, e, no caso inglês, foi um discurso usado tanto para embasar partidários do rei, quanto partidários do parlamento, assim como os levellers e diggers, críticos de ambas as instituições. Nesse discurso, o termo "raça" não tem um sentido biológico marcado, mas se refere simplesmente a grupos com origens e costumes distintos (é o caso dos povos denominados galo-romanos, francos, saxões, normandos etc). Se, de um lado, esse discurso de guerra de raças era utilizado para questionar a soberania, por outro, também poderia ser usado para justificar a dominação ou para apontar a possibilidade dessa dominação ser revertida e justificar as revoltas. Foucault nos mostra que esse discurso se modifica substancialmente no século XIX. Essa mudança ocorre ao entrar em contato com vertentes da biologia nascente na época. De um discurso com versatilidade tática (usado para questionar ou justificar a dominação política), a visão de que a sociedade é perpassada por uma guerra entre raças torna-se um discurso médico-normalizador que tende a justificar e reorientar a soberania. Nesse caso, a ideia de guerra de raças perde o sentido guerreiro de luta e vitória e passa a assumir o sentido biológico de sobrevivência e seleção do mais forte. A ideia de que a sociedade é formada por grupos de origens distintas que se enfrentam, transforma-se numa visão monística de sociedade ameaçada por sujeitos 
desviantes ou sub-raças que ameaçam degenerar toda a sociedade. O Estado deixa de ser compreendido enquanto instrumento de dominação de uma raça contra outra (no sentido amplo e fluido de raça), e torna-se o protetor da integridade e pureza de uma raça, agora no sentido que a biologia da época conferia ao termo raça. ${ }^{26}$

É neste último momento que se constitui aquilo que Foucault chama de biopolítica. Neste período se constrói a especificidade do racismo biológico moderno - o racismo que moveu regimes como o nazismo, mas que também moveu a colonização da África pela Europa durante o século XIX, e que Foucault também encontra em certas práticas soviéticas quando se tratou de pensar os normais e os anormais do regime. Foucault chega ao final do curso marcando as diferenças entre o poder biopolítico e o poder soberano, mostrando, no entanto, que a biopolítica não substituiu a soberania, mas a recobriu e a subordinou à sua lógica.

Segundo Foucault, o poder soberano é fundamentalmente jurídico-político. Esta forma de poder se exerce ao máximo sempre do lado da morte, realizando o confisco da vida. Se, na situação de contrato os homens fundam um poder superior para poderem viver em paz entre si, esse poder se exerce reclamando a morte desses homens toda vez que o contrato é violado severamente ou em situações de guerra. Essa é a forma clássica de poder abordado na filosofia política. Mas o interesse de Foucault não é exatamente a constituição do soberano, e sim a constituição dos súditos. Para isso ele não se volta para a fundamentação do poder, mas para as várias tecnologias de controle utilizadas nas pontas mais terminais das instituições. É olhando para esse lado do "como" do poder, que Foucault detecta o surgimento de um poder que age sobre a mecânica dos corpos entre os séculos XVII e XVIII, visando extrair o máximo de trabalho desses corpos. Trata-se do já mencionado poder disciplinar. Mas entre os séculos XVIII e XIX começa a se constituir uma nova gama de mecanismos de controle que não visam mais o homem-corpo, mas o homem-espécie, os homens enquanto seres vivos. Trata-se de um poder que se aplica e se ocupa das taxas de natalidade, de mortalidade, da velhice, dos acidentes, das doenças que atingem uma população e acabam afetando a força de trabalho disponível: "Depois da anátomo-política do corpo humano, instaurada no decorrer do século XVIII, vemos 
aparecer, no fim do mesmo século, algo que já não é uma anátomo-política do corpo humano, mas que eu chamaria de uma 'biopolítica' da espécie humana". ${ }^{27}$ Assim, em relação ao antigo poder soberano, Foucault nos mostra a emergência recente de duas formas diferentes e complementares de exercício do poder. Uma que se exerce fundamentalmente no âmbito da individualização dos corpos, disciplinando-os, e outra, que se exerce gerindo a vida da espécie.

Contudo, como um poder que tem como função gerir e potencializar a vida biológica de uma população pode reclamar a morte tanto para outros povos quanto para seus próprios cidadãos? É neste ponto que funciona aquilo que Foucault chama de "racismo de Estado"28. Os mecanismos de regulação da vida da população fizeram com que o racismo assumisse uma nova faceta. Trata-se, agora, de um racismo que introduz um corte na continuidade biológica, corte este que separa quem deve viver de quem deve morrer. Trata-se também de um racismo em que a morte do outro ou sua submissão não desembocam numa vitória política que pode ser revertida, tal como naquele discurso de guerra das raças do século XVII. Nesta nova forma de racismo, a morte do outro desemboca numa intensificação da própria vida. Como afirma Foucault, "tirar a vida, o imperativo da morte, só é admissível no sistema do biopoder, se tende não à vitória sobre os adversários políticos, mas à eliminação do perigo biológico e ao fortalecimento, diretamente ligado a essa eliminação, da própria espécie ou da raça". ${ }^{29} \mathrm{Ou}$ seja, se na lógica biopolítica os massacres se tornam vitais, isso se dá na medida em que a morte apenas pode ser reclamada em nome da vida biológica da espécie, a qual precisaria assegurar sua pureza ou desenvolvimento.

$\mathrm{Na}$ primeira metade do século XX, a biopolítica desemboca em sua forma mais assassina no regime nazista. No entanto, ela também estava presente em regimes que nunca foram totalitários e que até lutaram contra os nazistas, uma vez que a lógica racista também propulsionou a colonização do século XIX. De acordo com Foucault,

No fundo, o evolucionismo, entendido num sentido lato - ou seja, não tanto a própria teoria de Darwin quanto o conjunto, o pacote de suas noções (como: hierarquia das espécies sobre a árvore comum da evolução, luta pela vida entre

\footnotetext{
${ }^{27}$ FOUCAULT, 1999, p. 289

${ }^{28}$ FOUCAULT, 1988 , p. 130.

${ }^{29}$ FOUCAULT, 1999, p. 306.
} 
as espécies, seleção que elimina os menos adaptados) -, tornou-se, em alguns anos do século XIX, não simplesmente uma maneira de transcrever em termos biológicos o discurso político, não simplesmente uma maneira de ocultar o discurso político sob uma vestimenta científica, mas realmente uma maneira de pensar as relações da colonização, a necessidade das guerras, a criminalidade, os fenômenos da loucura e da doença mental, a história das sociedades com as classes, etc (...). O racismo vai se desenvolver primo com a colonização, ou seja, com o genocídio colonizador. Quando for preciso matar pessoas, matar populações, matar civilizações, como se poderá fazê-lo, se se funcionar no modo do biopoder? Através dos temas do evolucionismo, mediante um racismo. ${ }^{30}$

Deste modo, se um poder encarregado de gerir e melhorar a vida de uma população precisar mobilizar o velho poder soberano para matar, ele vai funcionar a partir de uma lógica racista, desse corte racista entre vida a ser defendida e vida a ser eliminada. Nesse caso Foucault faz uma afirmação interessante para pensarmos nosso momento atual: "por tirar a vida não entendo simplesmente o assassínio direto, mas também tudo o que puder ser assassínio indireto: o fato de expor à morte, de multiplicar para alguns o risco de morte ou, pura e simplesmente, a morte política, a expulsão, a rejeição, etc.". ${ }^{31}$ Não se trata apenas de matar, mas de deixar morrer, expor uma parcela da população a riscos muito maiores que outra parcela.

Mas qual a atualidade desse tipo de reflexão, uma vez os discursos defensores de um racismo biológico não se sustentam atualmente? Seja no nível acadêmico-científico, nos meios jurídicos, na imprensa ou na maior parte do âmbito político-partidário estes discursos, quando explícitos, são rechaçados e tomados com escândalo. Entretanto, esta genealogia tem importância não somente para a compreensão de nosso passado próximo, um tempo que muitas vezes não passa, pois ecoa em modos de pensar e de fazer das pessoas e das instituições. ${ }^{32} \mathrm{O}$ valor da análise foucaultiana está em mostrar que a lógica assassina da biopolítica, levada ao extremo nos regimes totalitários, utiliza "as ideias e os procedimentos de nossa racionalidade política." 33 Resguardando a singularidade histórica

\footnotetext{
${ }^{30}$ FOUCAULT, 1999, p. 307.

${ }^{31}$ FOUCAULT, 1999, p. 306.

${ }^{32}$ Nas Américas, todas essas ideais de degenerescência, de hierarquia de raças, atavismo, todas elas chegaram entre o final do século XIX e início do XX, e muitas vezes deram embasamento a políticas públicas. Ideias como as de Cesare Lombroso tiveram impacto em terras tupiniquins, e intelectuais brasileiros como Nina Rodrigues chegaram a desenvolver versões locais de teses racistas. O higienismo social fundamentou algumas das práticas políticas brasileiras, notadamente na forma com que se compreendia a pobreza, a criminalidade e os problemas sociais de um país com um grande número de escravos e libertos que, depois da abolição de 1888, formavam um conjunto que vivia em extrema pobreza.

${ }^{33}$ FOUCAULT, 1994d, p. 224
} 
dos regimes nazifascistas e stalinista, trata-se, para Foucault, de exercer uma função fundamental à filosofia em tempos de gestão política da vida, a saber, "vigiar os poderes excessivos da racionalidade política." ${ }^{34}$ Em resumo, a importância desta reflexão de Foucault sobre a relação entre racismo e biopolítica está no fato de que ela nos mostra como estes excessos são construídos sob as bases de saberes e imperativos econômicopolíticos compartilhados por diversos espectros do pensamento atual. No entanto, tal relação nem sempre é percebida quando camuflada por uma suposta neutralidade de discursos com pretensões de verdade. Deste modo, para realizar uma leitura rigorosa dos fenômenos sociais que estamos vivendo, é preciso compreender como a gestão dos fenômenos vitais em massa de uma população é alvo de ocupação política, que no caso brasileiro ainda é atravessada pelos racismos coloniais.

\section{Biopolítica, análise discursiva e a pandemia no Brasil}

Levando em consideração os elementos do pensamento foucaultiano trazidos até então, podemos interrogar: através de qual racionalidade política o governo federal brasileiro está lidando com pandemia do novo coronavírus? Como ele justifica suas ações? Seria demasiadamente apressado pressupor simplesmente a ausência de uma racionalidade em vistas da sua desarticulação ou despreparo aparentes. Sua resposta inicial, e mesmo depois da marca de cem mil mortos, não coloca como prioridade a contenção da contaminação. O isolamento vertical defendido inicialmente pelo governo, além de não ser aconselhado por autoridades competentes ${ }^{35}$, não era factível e sequer foi apresentado um planejamento para organiza-lo. Podemos afirmar que a estratégia está sendo deixar a doença proliferar mesmo sem o recurso a documentos oficiais que definam positivamente ser esta a estratégia. Talvez seja suficiente analisarmos discursos de membros do governo, e compararmos com as práticas do governo. Nesse caso, para

\footnotetext{
${ }^{34}$ FOUCAULT, 1994d, p. 224.

35 Sobre isso, ver a entrevista com o epidemiologista Pedro Hallal, da UFPel <https://www.uol.com.br/vivabem/noticias/bbc/2020/07/20/esperar-imunidade-de-rebanho-e-absurdo-eantietico-diz-lider-de-estudo-que-investiga-quantos-tiveram-covid-19-no-brasil.htm> acessado em 03/09/2020. Sobre posicionamento da OMS, ver a matéria disponível em: <https://saude.estadao.com.br/noticias/geral,omsdiz-que-imunidade-de-rebanho-nao-e-salvacao-da-pandemia,70003403451> acessado em 03/09/2020. Sobre a reação da comunidade científica britânica à estratégia de deixar o vírus circular, para ganhar a imunidade de rebanho (que deveria ser estratégia apenas para vacinação e não para adoecimento), ver a matéria do início da pandemia na Europa: <https://www.bbc.com/portuguese/internacional-51901822> acessada em 03/09/2020.
} 
facilitar, não há muitas contradições entre o discurso do executivo e a prática, exceto algumas no início da pandemia - logo resolvidas com a demissão de dois ministros da saúde em curto espaço de tempo. As reiteradas declarações de que o problema era muito menor que aquilo que era noticiado, as quais se transformaram em chantagem de salvar a economia, e o total descaso com o número galopante de mortos, são sintomáticos de uma forma de gestão da vida.

Em 24 de março, quando o país contava com 47 mortes, durante declaração em rede nacional, o presidente da República, Jair Messias Bolsonaro diz que, se contraísse a doença, devido a seu histórico de atleta, nada aconteceria com ele. No dia 26, com 77 mortes, afirma que o brasileiro tem que ser estudado, pois "Você vê o cara pulando em esgoto ali, sai, mergulha, tá certo? E não acontece nada com ele" ${ }^{36}$. Em 29 de março, com 139 mortos, o presidente diz que o vírus é uma realidade, mas que devemos enfrenta-lo como homem e não como moleque, pois é a vida, todos nós iremos morrer um dia ${ }^{37}$. Em 3 de abril, com 365 mortes, Bolsonaro diz que o vírus é como uma chuva, que vai molhar $70 \%$ dos brasileiros ${ }^{38}$. A mesma afirmação foi repetida pelo presidente durante um passeio de jet-ski no lago Paranoá em Brasília. Na ocasião, Bolsonaro encontra com pessoas que estão numa lancha fazendo um churrasco e lhe oferecem um espeto. Tratam-se de pessoas que se dizem do setor de aviação, que estavam sentindo bastante os efeitos das restrições - apesar de poderem estar passeando de lancha e fazendo churrasco em meio à crise do setor aéreo na pandemia. Então Bolsonaro afirma novamente que o vírus irá atingir 70\% dos brasileiros ${ }^{39}$. O modo e o contexto nos quais é afirmado este discurso é bastante significativo na construção do sujeito enunciativo.

Tudo isso foi dito e repercutido enquanto se constatava o que o vírus causava na China e na Europa. Num estudo estatístico, inicialmente o Imperial College de Londres estimou 1,15 milhão de mortos no Brasil caso nenhuma medida de enfrentamento fosse

\footnotetext{
${ }^{36}$ Esta declaração e a anterior foram retiradas da reportagem "Veja frases de Bolsonaro durante a pandemia do novo coronavírus", do G1, 2020b, a qual contém as devida gravações de áudio. Disponível em <https://g1.globo.com/politica/noticia/2020/04/30/veja-frases-de-bolsonaro-durante-a-pandemia-do-novocoronavirus.ghtml>, acessado em 05/08/2020.

${ }^{37}$ IDEM.

${ }^{38}$ IBDEM.

${ }^{39}$ Retirado da reportagem "Bolsonaro passeia de jet ski e diz que Brasil vive neurose com novo coronavírus", com material de vídeo através do UOL: <https://www.youtube.com/watch?v=AcLmjvl45nI> acessado em 01/05/2020.
} 
implementada e 519 mil mortos caso conseguíssemos isolar apenas os idosos. ${ }^{40}$ Esse tipo de atitude é um cálculo de gestão da vida de uma população. Isso é deixar morrer, mas em nome do quê? Em nome de salvar 'a economia', o que na verdade deveria ser corrigido por 'salvar uma forma de economia'.

Contudo, é preciso ressaltar que esse tipo de cálculo que manifesta desprezo pelas vidas não parece uma exceção na sociedade brasileira. Desde o início do século, convivemos em nosso país com números de homicídios que variam entre 48 e 65 mil por ano ${ }^{41}$. Um relatório do Conselho Nacional do Ministério Público, de 2012, aponta ainda que mais de $90 \%$ destes homicídios não são solucionados. ${ }^{42}$ Esses são números comparáveis a guerras civis, mas não causam a mesma impressão e nem a mesma comoção. A polícia brasileira também é uma das que mais mata e que mais morre no mundo, ${ }^{43}$ recebendo uma estrutura de impunidade ${ }^{44}$ por seus abusos em nome de uma política de segurança que ajuda a produzir parte desses homicídios. A grande maioria das vítimas das ações policiais são pobres e negros. Ainda há outros indicadores de mostram como os mais pobres, geralmente também negros, têm os piores índices de acesso a saúde e educação, e ganham salários menores, isso numa das economias mais desiguais do mundo. ${ }^{45}$

Neste sentido, ao que parece, essa exposição a maiores riscos articula-se a piores condições de vida, indicando o corte biopolítico entre quem deve viver e quem pode ou deve morrer no Brasil. Deixar o vírus circular na população nada mais é que reforçar e

\footnotetext{
${ }^{40}$ Um resumo com os dados do estudo do Imperial College pode ser encontrado na seguinte matéria do site G1, 2020a, "Sem isolamento e ações contra a Covid-19, Brasil pode ter até 1 milhão de mortes na pandemia, diz estudo". Disponível em <https://g1.globo.com/bemestar/coronavirus/noticia/2020/03/27/sem-isolamento-e-acoescontra-a-covid-19-brasil-pode-ter-ate-1-milhao-de-mortes-na-pandemia-diz-estudo.ghtml>, acessado em 01/09/2020.

${ }^{41}$ Dado retirado do Atlas da Violência, do Instituto de Pesquisa Econômica Aplicada (IPEA). Disponível em <https://www.ipea.gov.br/atlasviolencia/dados-series/17> acessado em 06/09/2020.

${ }^{42}$ CONSELHO NACIONAL DO MINISTÉRIO PÚBLICO, 2012, p. 22.

${ }^{43}$ Ver o artigo de Olga Câmara, "Polícia brasileira: a que mais mata e a que mais morre". Disponível em <https://jus.com.br/artigos/74146/policia-brasileira-a-que-mais-mata-e-a-que-mais-morre> acessado em $06 / 09 / 2020$.

44 Segundo reportagem de Gil Alessi, disponível em < https://brasil.elpais.com/brasil/2017/07/21/politica/1500662148_452392.html > acessada em 05/09/2020.

${ }^{45}$ A reportagem de Bermúdez, Rezende e Madeiro, 2019, "Brasil é o $7^{\circ}$ país mais desigual do mundo, melhor apenas do que africanos", cita o relatório de desenvolvimento humano do Programa das Nações Unidas para o Desenvolvimento, que mostra o Brasil como o sétimo país mais desigual do mundo. Disponível em <https://noticias.uol.com.br/internacional/ultimas-noticias/2019/12/09/brasil-e-o-7-mais-desigual-do-mundomelhor-apenas-do-que-africanos.htm>, acessado em 07/09/2020.
} 
radicalizar esse corte, realizado por características econômico-sociais, que já existe muito antes da pandemia. Contudo, este corte biopolítico não é produzido apenas pelo Estado brasileiro, mas na relação deste para com outros agentes, notadamente grupos detentores de grandes riquezas. No início de maio, quando o Brasil já tinha mais de 7.000 mortos, Guilherme Benchimol, o presidente e fundador de uma das maiores corretoras de investimentos do país disse:

\begin{abstract}
Acompanhando um pouco os nossos números, eu diria que o Brasil está bem. Nossas curvas não estão tão exponenciais ainda, a gente vem conseguindo achatar. Teremos uma fotografia melhor nas próximas duas ou três semanas. $\mathrm{O}$ pico da doença já passou quando a gente analisa a classe média, classe média alta. O desafio é que o Brasil é um país com muita comunidade, muita favela, o que acaba dificultando o processo todo. ${ }^{46}$
\end{abstract}

Metade dos brasileiros vive com, em média, $\mathrm{R} \$ 413$ mensais ${ }^{47}$ (aproximadamente 78 dólares na cotação atual e 137 caso o dólar valesse $\mathrm{R} \$ 3,00)$. Mais da metade da população do Brasil vive com dificuldades financeiras devido a baixa renda, pois dificilmente se pode afirmar que mesmo pessoas que ganham um salário mínimo ou pouco mais vivem tranquilamente. Contudo, o empresário considera que é a existência dessas pessoas que dificulta o processo para se lidar com a pandemia. O racismo aqui aparece de modo pouco velado, mas ainda assim não é explícito. Sua preocupação com os riscos da pandemia define claramente um corte biopolítico no qual se pauta a questão da pandemia pela saúde das classes maior poder aquisitivo. O empresário até diz saber do desafio que há em pedir para as pessoas ficarem em casa, visto o alto grau de informalidade do trabalho no Brasil. Mas a respeito da crise política daquele momento ele afirma: "se não afetar a economia e as reformas continuarem avançando, a crise política não atrapalha, é muito mais um barulho de curto prazo" 48 . Contudo, são justamente tais reformas que defendem

\footnotetext{
${ }^{46}$ MOURA, 2020. Reportagem "Pico de Covid-19 nas classes altas já passou; o desafio é que o Brasil tem muita favela, diz presidente da XP", Disponível em: <https://www1.folha.uol.com.br/mercado/2020/05/brasil-esta-indobem-no-controle-do-coronavirus-e-pico-nas-classes-altas-ja-passou-diz-presidente-da-xp.shtml $>$ acessado em 05/08/2020.

${ }^{47}$ De acordo com a matéria de Heloísa Mendonça, 2019, "Viver com 413 reais ao mês, a realidade de metade do Brasil”. Disponível em <https://brasil.elpais.com/brasil/2019/10/30/economia/1572454880_959970.html> acessada em 01/05/2020.

${ }^{48}$ MOURA, 2020.
} 
austeridade a todo custo, que precarizam as condições de trabalho ${ }^{49}$ e que aumentam as desigualdades, as quais incidem numa sociedade já marcada por um passado recente de escravidão. São reformas que dão continuidade às práticas políticas responsáveis por fazer com que o acesso à saúde, moradia, saneamento básico e condições dignas de vida seja raro no Brasil. Neste sentido, entrevistada em reportagem da BBC News Brasil, Emanuelle Góes, parece resumir as implicações da pandemia:

O que a pandemia tem evidenciado é o que vários estudos já mostravam em relação ao maior prejuízo da população pobre e negra ao acesso da saúde. A covid-19 encontra um terreno favorável porque essas pessoas estão em um cenário de desigualdade de saúde e de precarização da vida ${ }^{50}$.

\section{Considerações finais: alguns elementos para um diagnóstico da biopolítica no Brasil durante a pandemia de COVID-19.}

Vivenciando um momento particularmente inesperado e com um campo de análises ainda pouco delimitado, certamente, estamos num terreno muito mais movediço que aquele investigado por Foucault. Ao invés de vários saberes, analisados em suas relações com um conjunto de práticas institucionais, estamos no terreno das declarações e ações políticas de um governo específico durante uma pandemia que ainda está em curso. Contudo, mesmo com essas limitações, a análise foucaultiana nos permite afirmar que é mais proveitoso compreender os discursos das autoridades brasileiras tentando traçar seus desempenhos táticos e compreender o espaço em que eles têm lugar, do que apenas denunciar suas mentiras. As mentiras do governo brasileiro só têm espaço dentro de um conjunto de procedimentos em que sistemas de verdade sobre a população são possíveis. É somente por uma recusa em reconhecer o que os saberes biopolíticos mostram que podemos afirmar a falsidade das declarações governamentais. É neste espaço em que o objeto população ganha densidade entre os dados que dizem respeito a sua saúde, que fica

\footnotetext{
${ }^{49}$ De acordo com a matéria de Manuel Gómez, 2017, “A reforma da Espanha que inspirou Temer: mais empregos (precários) e com menores salários". <https://brasil.elpais.com/brasil/2017/04/27/internacional/1493296487_352960.html> acessada em 01/05/2020. Para uma perspectiva mundial ver o relatório da Oxfam de 2018, na matéria "Super-ricos estão ficando com quase toda riqueza, às custas de bilhões de pessoas". Disponível em $<$ https://www.oxfam.org.br/noticias/super-ricosestao-ficando-com-quase-toda-riqueza-as-custas-de-bilhoes-de-pessoas/> acessado em 01/05/2020.

${ }^{50}$ GRAGNANI, 2020. Reportagem: "Por que o coronavírus mata mais as pessoas negras e pobres no Brasil e no mundo", disponível em <https://www.bbc.com/portuguese/brasil-53338421> Acessado em 05/08/2020.
} 
manifesta a impostura de uma gestão governamental que se recusa a priorizar uma gestão não hierarquizada das vidas. Da mesma forma que a simples denuncia das falsidades, também o critério de preparo ou despreparo de agentes estatais parece demasiado restrito, pois impede que se interrogue pela racionalidade estratégica própria dos discursos e das ações implementadas. Se compreendermos que os discursos, por mais absurdos que possam parecer, são parte de estratégias para provocar determinados efeitos na realidade (através de um conjunto múltiplo que envolve a mobilização de pessoas, ocultação e distorção de dados e informações, criação de falsas ameaças internas e externas, partidarização de tratamentos sem comprovação), talvez possamos compreender melhor essa racionalidade da gestão da vida durante a pandemia de COVID-19 no Brasil.

Ao considerar um discurso em sua racionalidade estratégica, pode-se afirmar que minimizar a gravidade da pandemia não é apenas um despreparo ou uma forma de enganar. Trata-se de uma estratégia discursiva que visa produzir vários efeitos, dentre os quais, fazer com que parte da população descumpra as regras e conselhos de isolamento que estados e municípios procuravam implementar no início da pandemia. Trata-se de minar as políticas de isolamento propostas por outras autoridades para o combate à pandemia. Ao mesmo tempo, os discursos do governo federal buscam transformar a gestão da pandemia num embate político-partidário nos moldes eleitorais, em que alguns governadores podem ser candidatos adversários na busca de uma reeleição do atual governo. Consequentemente, também é uma forma de garantir a propagação do vírus, isentando-se da responsabilidade pelos efeitos econômicos do isolamento parcial e pouco criterioso que se deu justamente pela falta de coordenação entre governos federal, estadual e municipal; neste caso, impedindo um isolamento mais rigoroso com suas mensagens, o governo federal sabota os planos de estados e municípios, ao mesmo tempo em que pode acusa-los de terem um plano ruim, e ainda culpa-los pela crise econômica. Minimizar a pandemia ainda pode ser uma forma de proporcionar maior entusiasmo com uma suposta figura viril do presidente e dar a impressão de coragem à base popular de apoio do governo. Tomar o caso individual da eventual contaminação de um presidente enquanto paradigma de como lidar com a doença no país, sendo que este possui uma equipe médica ao seu redor tal como quase ninguém no Brasil possui, também é uma forma de estimular a população a se expor a mais riscos e a desrespeitarem regras e conselhos de isolamento. 
Ao mesmo tempo, é uma forma de cultivar a imagem até certo ponto messiânica da sua pessoa, e estimular valores de capacitismo e masculinidade tóxica ${ }^{51}$. Afirmar a necessidade de se enfrentar o coronavírus como homens é fazer pouco caso da responsabilidade individual e coletiva perante a possibilidade de contaminação de si e dos outros, e transformar a escolha individual em valor superior a qualquer forma de exposição do outro a riscos. Transformar casos individuais em que a doença se manifesta de modo assintomático ou com sintomas leves em paradigma de tratamento também é reforçar o capacitismo, criando a imagem do que deve ser o corpo ideal a ser defendido, sendo todos os outros corpos relegados ao outro lado da linha biopolítica, o das vidas descartáveis ${ }^{52}$. Finalmente, de um modo que não poderemos desenvolver em toda sua complexidade, esta atitude revela o contrário da coragem que busca aparentar à sociedade: trata-se de uma atitude pusilânime, pois o governo possui condições materiais de ajudar a conter o surto, especialmente em seu início, mas acabou fazendo propositalmente o contrário, e ainda demonstrou pouco caso da morte e sofrimento dos atingidos.

Se considerarmos os discursos e práticas governamentais brasileiras em seus efeitos estratégicos, também podemos começar a dar conta de outra especificidade da gestão biopolítica da pandemia no Brasil. Os saberes reconhecidos como científicos, chancelados pelas instâncias de validação como universidades e institutos de pesquisa, foram considerados enquanto inimigos a serem combatidos $^{53}$. Isso significa que a articulação poder-saber-ética se apresenta com os saberes institucionalizados cientificamente desempenhando um papel majoritariamente crítico da gestão da pandemia no Brasil especialmente a epidemiologia, a infectologia e a biologia. Contra estes saberes, são mobilizadas notícias falsas sobre conspirações e curas não comprovadas, difundidas em

\footnotetext{
${ }^{51}$ Sobre isso ver o texto "Dissecando o autoritarismo relutante e capacitista frente ao coronavírus no Brasil", de Francisco Ortega e Michael Orsini. Disponível em < https://n-1edicoes.org/031> acessado em 03/09/2020.

${ }^{52}$ É preciso ressaltar que esse discurso não parece apenas defender o individualismo. Trata-se também de criar um ente coletivo, aquele dos 'homens de verdade' ou 'cidadãos de bem', que não têm medo do vírus e que estão dispostos a arriscar suas vidas na defesa do governo e, mais especificamente, da pessoa do presidente. Ao mesmo tempo, fora dessa comunidade estão todas as ameaças ao Brasil. Neste sentido, a criação dessa identidade coletiva mediante tal estratégia discursiva do governo gera um clima social de guerra civil no país.

${ }^{53}$ Trata-se de uma atitude semelhante àquela tomada diante da divulgação do aumento do desmatamento na floresta amazônica pelo Instituto Nacional de Pesquisas Espaciais. Neste caso, o governo atacou a credibilidade do instituto sem ter qualquer base para isso, e exonerou seu diretor. Sobre isso ver a reportagem de NOVAES, 2019 , “"Constrangimento' com Bolsonaro por dados de desmatamento derruba diretor do Inpe”. Disponível em <https://brasil.elpais.com/brasil/2019/08/02/politica/1564759880_243772.html> acessada em 05/09/2020.
} 
grupos de aplicativos de mensagens com amplo alcance. Neste caso, o objetivo é mobilizar a população a defender toda e qualquer medida do governo e a voltar-se contra toda forma de crítica. Contudo, os ataques a esses saberes não se dá devido aos seus conteúdos, mas sim devido ao amplo consenso de que se deve evitar o maior número de contágios e de mortos. Agências de inteligência fornecem ao governo informações baseadas justamente em estatísticas epidemiológicas ${ }^{54}$. Logo, ao que parece, a questão sensível é justamente tentar alterar o corte biopolítico que separa vidas a serem defendidas, e vidas que podem ser expostas ao risco de morte e sequelas da infecção. Na medida em que estes saberes sustentam a necessidade de isolamento social para a contenção do contágio em toda população, eles se tornam adversários das estratégias políticas do governo.

Neste sentido, estamos em pleno terreno biopolítico de gestão da vida de uma população. Contudo, não seria apropriado usar o termo biopolítica apenas enquanto atributo negativo para classificar um conjunto de ações pois, do ponto de vista foucaultiano, enquanto a vida da população for o objeto de intervenções políticas, seja para promover a saúde de uns ou a morte de outros, estamos dentro do seu terreno. Os embates atuais no Brasil são um exemplo disso, pois se deram entre distintas estratégias de gestão da vida na pandemia, sendo a opção de gestão do governo a de manter e radicalizar o corte biopolítico pré-existente na sociedade brasileira. Evidentemente, há riscos significativos para a parcela mais rica da população, cujas vidas estão entre aquelas que devem ser defendidas, segundo o funcionamento biopolítico tradicional do país. No entanto, estes riscos são muito inferiores em comparação àqueles que atingem a parcela que anteriormente já vivia em condições precárias. Parte do papel de crítica do poder desempenhado pelos saberes científicos talvez tenha vindo justamente por eles sugerirem práticas que questionaram o corte biopolítico que já marcava a sociedade brasileira antes da pandemia. Estes saberes também apontam para a importância das características econômicas e sociais de diferentes parcelas da população enquanto fatores de risco, o que tende a coloca-los em posição conflituosa com estratégias que visam a manutenção e radicalização destes mesmos fatores - incluindo o âmbito das políticas econômicas. O

\footnotetext{
${ }^{54}$ De acordo com a matéria, de Rafael Moro Martins e Leandro Demori, intitulada "Exclusivo: Abin fala em 5,5 mil mortes em 15 dias enquanto Bolsonaro chama coronavírus de histeria", publicada no site The Intercept Brasil. Disponível em <https://theintercept.com/2020/03/24/coronavirus-abin-projeta-mortes/>, acessada em 05/09/2020.
} 
sanitarismo que, no século XIX e início do XX, era frequentemente atravessado por teses racistas e outros discursos que justificavam a estrutura social brasileira, hoje se transformou num conjunto de saberes muito mais atentos para as articulações entre estruturas sociais e saúde.

Por conseguinte, na medida em que essa pandemia evidencia como nosso passado colonial, nossos racismos e extrema desigualdade social marcam a divisão entre aqueles cujas vidas devem ser preservadas, e aquelas vidas que podem ser abandonadas à morte, a noção de biopolítica de Foucault, apesar de seus limites e de precisar ser complementada, ainda se mantém atual enquanto ferramenta de análise. $\mathrm{O}$ deslocamento do olhar, que passa da classificação entre verdadeiro ou falso para a interrogação das estratégias e efeitos de realidade que determinados discursos visam, também enriquece a análise da gestão da pandemia. Nesta perspectiva, tanto os discursos oficiais enganosos quanto as notícias falsas que circulam em grupos de aplicativos, por mais estapafúrdias que sejam, passam a ser encarados enquanto instrumentos de mobilização social e de criação de um ethos militante conservador, perpassado por valores de competição e capacitistas, sempre pronto para a incondicional defesa das estratégias do governo.

Neste artigo, no entanto, os elementos que apontamos como relevantes para a análise da situação brasileira promovem apenas um esboço inicial para a elaboração de um diagnóstico do presente. Tal diagnóstico, segundo Foucault,

(...) não consiste em simplesmente caracterizar aquilo que somos, mas, seguindo as linhas de fragilidade da atualidade, trata-se de conseguir apreender por onde e como isso que é poderia não mais ser isso que é. E é neste sentido que a descrição deve sempre ser feita segundo esta espécie de fratura virtual que abre um espaço de liberdade, compreendida como espaço de liberdade concreta, a saber, de transformação possível (FOUCAULT, 1994d, pp.448-449).

Neste sentido, descrever estas estratégias de gestão biopolítica da pandemia também deve ser uma forma de mostrar a importância de um conjunto de práticas que tornaram possível que um governo destinasse um grande número de pessoas à contaminação e todos os seus riscos. Da mesma forma, deve apontar a possibilidade de que outra forma de gestão implica numa alteração de todos os fatores que desenham o corte biopolítico que separa as poucas vidas que importam, e as muitas que não importam no Brasil. 


\section{Bibliografia:}

AGAMBEN, G. Homo Sacer: o poder soberano e a vida nua I. Belo Horizonte: Editora UFMG, 2002.

"La invención de una pandemia". In: Sopa de Wuhan. Pensamiento contemporáneo en tiempos de pandemias. Editorial ASPO (Aislamiento Social Preventivo y Obligatorio), 2020.

ALESSI Gil. "PMs, juízes, promotores e nós: o complexo ciclo da violência policial" Disponível em https://brasil.elpais.com/brasil/2017/07/21/politica/1500662148_452392.html > acessado em 05/09/2020.

BERARDI, F. 'BIFO'. "Crónica de la psicodeflación." In: Sopa de Wuhan. Pensamiento contemporáneo en tiempos de pandemias. Editorial ASPO (Aislamiento Social Preventivo y Obligatorio), 2020.

BERMÚDEZ, A. C.; REZENDE, C. e MADEIRO, C. "Brasil é o $7^{\circ}$ país mais desigual do mundo, melhor apenas do que africanos". UOL, 2019. Disponível em <https://noticias.uol.com.br/internacional/ultimas-noticias/2019/12/09/brasil-e-o-7mais-desigual-do-mundo-melhor-apenas-do-que-africanos.htm $>, \quad$ acessado em 07/09/2020.

CÂMARA, O. "Polícia brasileira: a que mais mata e a que mais morre". Jus.com.br. 2019. Disponível em <https://jus.com.br/artigos/74146/policia-brasileira-a-que-mais-mata-ea-que-mais-morre>, acessado em 06/09/2020.

CONSELHO NACIONAL DO MINISTÉRIO PÚBLICO. Relatório Nacional da Execução da Meta 2: um diagnóstico da investigação de homicídios no país. Brasília: Conselho Nacional do Ministério Público, 2012.

ESPOSITO, R. Bíos: biopolítica e filosofia. Belo Horizonte: Editora UFMG, 2017.

FOUCAULT, M. Em defesa da sociedade: curso no Collège de France (1975-1976). São Paulo: Martins Fontes, 1999. (Coleção tópicos)

. Dits et écrits vol. I. Paris: Éditions Gallimard, 1994.

. Dits et écrits vol. II. Paris: Éditions Gallimard, 1994.

Dits et écrits vol. III. Paris: Éditions Gallimard, 1994.

. Dits et écrits vol. IV. Paris: Éditions Gallimard, 1994.

História da sexualidade I: A vontade de saber. Rio de Janeiro: Edições Graal, 1988. 
. L'arquéologie du savoir. Paris: Éditions Gallimard, 1969.

. Vigiar e punir: nascimento da prisão. Petrópolis: Vozes, 2008.

GÓMES, M. V. "A reforma da Espanha que inspirou Temer: mais empregos (precários) e com menores salários". El país, Madri, 27 de abril de 2017. Seção Internacional. Disponível em:

<https://brasil.elpais.com/brasil/2017/04/27/internacional/1493296487_352960.html $>$ acessada em 01/05/2020.

GRANANI, J. "Por que o coronavírus mata mais as pessoas negras e pobres no Brasil e no mundo". BBC News Brasil, Londres, 12 de Julho de 2020. Disponível em < https://www.bbc.com/portuguese/brasil-53338421 > Acessado em 05/08/2020.

IPEA. Atlas da violência. 2020. Disponível em $<$ https://www.ipea.gov.br/atlasviolencia/dados-series/17> acessado em 06/09/2020. MARTINS, R. M.; DEMORI, L. "Exclusivo: Abin fala em 5,5 mil mortes em 15 dias enquanto Bolsonaro chama coronavírus de histeria". The Intercept Brasil, 2020. Disponível em <https://theintercept.com/2020/03/24/coronavirus-abin-projeta-mortes/>, acessada em 05/09/2020.

MARX, K. "1. ad Feuerbach (1845)". In: MARX, K; ENGELS, F. A ideologia alemã: crítica da mais recente filosofia alemã em seus representantes Feuerbach, B. Bauer e Stirner, e do socialismo alemão em seus diferentes profetas (1845-1846). São Paulo: Boitempo, 2007.

MENDONÇA, H. "Viver com 413 reais ao mês, a realidade de metade do Brasil". El país, São Paulo, 04 de novembro de 2019. Disponível em <https://brasil.elpais.com/brasil/2019/10/30/economia/1572454880_959970.html> acessada em 01/05/2020.

MOURA, J. "Pico de Covid-19 nas classes altas já passou; o desafio é que o Brasil tem muita favela, diz presidente da XP". Folha de São Paulo, São Paulo, 05 de maio de 2020. Seção Coronavírus. Disponível em $<$ https://www1.folha.uol.com.br/mercado/2020/05/brasil-esta-indo-bem-no-controledo-coronavirus-e-pico-nas-classes-altas-ja-passou-diz-presidente-da-xp.shtml> acessado em 05/08/2020.

NIETZSCHE, F. Genealogia da moral: uma polêmica. São Paulo: Companhia das Letras, 2009. 
NOVAES, M. “'Constrangimento’ com Bolsonaro por dados de desmatamento derruba diretor do Inpe". El País, São Paulo, 02 de agosto de 2019. Disponível em <https://brasil.elpais.com/brasil/2019/08/02/politica/1564759880_243772.html> acessado em 05/09/2020.

ORTEGA, F.; ORSINI, M. "Dissecando o autoritarismo relutante e capacitista frente ao coronavírus no Brasil." In: Pandemia Crítica. São Paulo, N-1, 2020. Disponível em https://n-1edicoes.org/031. Consultado em 12.06.2020.

ZIZEK, S. "El coronavirus es un golpe al capitalismo a lo Kill Bill." In: Sopa de Wuhan. Pensamiento contemporáneo en tiempos de pandemias. Editorial ASPO (Aislamiento Social Preventivo y Obligatorio), 2020.

“CORONAVÍRUS (COVID-19) Mortality Rate”. Worldometers, 2020. Disponível em $<$ https://www.worldometers.info/coronavirus/coronavirus-death-rate/>, acessado em 05/08/2020.

"SEM isolamento e ações contra a Covid-19, Brasil pode ter até 1 milhão de mortes na pandemia, diz estudo". G1, 2020a. Disponível em https://g1.globo.com/bemestar/coronavirus/noticia/2020/03/27/sem-isolamento-eacoes-contra-a-covid-19-brasil-pode-ter-ate-1-milhao-de-mortes-na-pandemia-dizestudo.ghtml, acessado em 01/09/2020.

"SUPER-RICOS estão ficando com quase toda riqueza, às custas de bilhões de pessoas". Oxfam Brasil, 2018. Disponível em <https://www.oxfam.org.br/noticias/super-ricosestao-ficando-com-quase-toda-riqueza-as-custas-de-bilhoes-de-pessoas $/>$ acessado em $01 / 05 / 2020$.

"VEJA frases de Bolsonaro durante a pandemia do novo coronavírus". G1, 2020b. Disponível em https://g1.globo.com/politica/noticia/2020/04/30/veja-frases-debolsonaro-durante-a-pandemia-do-novo-coronavirus.ghtml, acessado em 05/08/2020. 